\title{
Use of Recycled Aggregates made from Construction and Demolition Waste from Structural Concrete such as Graded Aggregate and Cement Soil in Sustainable Road Infrastructures Base Layers
}

\author{
Evelio Teijón-López-Zuazo 1,*, Ángel Vega-Zamanillo 2 ${ }^{2}$, Miguel Ángel Calzada-Pérez ${ }^{2}$ and \\ Ángel Robles Miguel ${ }^{1}$ \\ ${ }^{1}$ Construction and Agronomy Department, Zamora Polytechnical School, Viriato Campus, University of \\ Salamanca, 49022 Zamora, Spain; eteijon@usal.es (E.T.-L.-Z.); arm@usal.es (A.R.-M.) \\ 2 Department of Transportation and Projects and Processes Technology, Civil Engineering Technical \\ School of Santander, University of Cantabria, Los Castros Avenue, 39005 Santander, Spain; \\ vegaa@unican.es (A.V.-Z.); calzadam@unican.es (M.A.C.-P) \\ * Correspondence: eteijon@usal.es
}

\begin{abstract}
Construction and demolition waste (CDW) represents $1 / 3$ of the weight of all-waste produced. Increasing their recycling and reutilization with recycled aggregates (RA) means closing the life cycle of construction materials. Research has been carried out on artificial aggregates from the exclusive crushing of structural concrete waste in selective demolitions (CDWRConc). This study analyses the use of recycled concrete as graded aggregate (GARConc) and in cement soil (CSRConc). The material complies with the requirements as a road base, although due to the low values of resistance to fragmentation these materials are adequate for use in sensitive road systems and other places such as urban roads and car parks. The sensitive road systems are infrastructures in places of great natural wealth and low traffic intensity, with an annual average of heavy vehicle traffic (AADTh) below $50 \mathrm{vh} / \mathrm{d}$. As soluble salt contents have been detected, additional waterproofing or drainage measures must be adopted to prevent water infiltration into the layers made up of CDWRHorm. Finally, the high initial values of UCS allow the temporary passage of light vehicles over CSRConc after 3 days.
\end{abstract}

Keywords: Construction and Demolition Waste, recycled aggregate, structural concrete, absorption coefficient, graded aggregate, cement - soil, base layer.

\section{Introduction}

The European Union considers construction and demolition waste (CDW) the largest waste stream, around one third by weight of all waste produced. The Waste Framework Directive 2008/98/EC [1] aims to increase the re-use, recycling and other forms of recuperation of CDW to a minimum of $70 \%$ by weight in 2020 . This increase means closing the life cycle of construction materials by extending their useful life.

For Arshad and Ahmed [2] the increasing difficulties in finding natural aggregates means that extraction costs are increasing. This implies considering the recovery and recycling of old concrete structures as new sources of building materials. Materials containing between $50-75 \%$ of recycled asphalt pavement and $5.5-7.5 \%$ of aggregates from concrete crushing (CDWRConc) are analyzed. The results show the validity of the mixture as a granular base layer. The higher the proportion of CDWRConc, the lower the optimal moisture content in the modified Proctor test. Maximum densities between $20.7-20.3 \mathrm{kN} / \mathrm{m} 3$ were obtained. The application of concrete sub-products is limited due to the lack of testing and trials. The generalization of the use of recycled concrete products in road pavements requires the development of procedures and guidelines with design methods. 
The Spanish Waste Management Framework Plan [3] establishes for clean soil and stone waste, LER code 170504 [4], a minimum recycling percentage of 90\%. They can be used in earthworks and environmental restoration and conditioning work. Reuse and recycling should be encouraged by encouraging the use of CDWRConc on construction works. Public contracts should consider minimum percentages of recycled material use in public works, in the order of $5 \%$ in recycled aggregates. In Spain there is a production of CDW of $1 \mathrm{t}$ per inhabitant per year.

For Ebrahim Abu El-Maaty Behiry [5], environmental protection is a major concern in Egypt, where the increase in demolitions provides opportunities to incorporate recycled concrete aggregate into roadways. Unconfined compressive strength (UCS) is the most important quality indicator, with others being cement content, rupture time or dry density. The recycled concrete aggregates investigated have offered an internal friction angle of $47^{\circ}$ and an absorption coefficient of $2.25 \%$. A UCS value of $2.56 \mathrm{MPa}$ at 7 days has been obtained for a cement content of $5.0 \%$.

The Catalogue of pavements and construction units with recycled aggregates from Construction and Demolition Waste [6] proposes the development of design guidelines or calculation recommendations to facilitate the design for designers. The use of recycled aggregates should be evaluated from environmental aspects, considering the advantage of using CDW as a new resource without the need to consume natural resources. Although there are important differences in the physical, chemical and mechanical characteristics of the RA's compared to natural aggregates, the RA can be applied to road pavements partly or fully substituting natural aggregates. The use of RA in pavement sections has offered a satisfactory performance in sections with a maximum $\mathrm{AADT}_{\mathrm{h}}=800 \mathrm{vhp} / \mathrm{d}$. In the $\mathrm{CDWRConc}$ were estimated values of $\mathrm{E}=500 \mathrm{MPa}$ and $\mathrm{v}=0.35$.

Cartuxo et al. [7] study the influence of 2 superplasticizers (SP) on the durability of concrete made with the fine fraction of CDWRConc. $0,10,30,50$ and 100\% replacement percentages were tested. The addition of recycled aggregate increases water absorption by immersion, capillary action, chloride migration coefficient and carbonation depth. The addition of superplasticizer produces a variation in properties. The water/cement ratio decreases by $25 \%$. The absorption decreases by $43 \%$. Water absorption by capillary action at $72 \mathrm{~h}$ decreased to $66 \%$. The carbonation depth at 91 days decreased to $80 \%$. Chloride migration coefficient decreased to $46 \%$. So, the mixture is a sustainable solution that complies with durability requirements.

The Guide to the use of recycled aggregates [8] calculates that the construction sector represents half of the materials extracted and energy used and approximately one third of the water consumed. The modified Proctor test in CDW should be performed after previous saturation. The test should be called the modified proctor test after saturation. The modified Proctor test after saturation must be performed at least one hour after saturation. This should be the time necessary to assure that the aggregates have completed their water absorption. Thus, for the correct use of CDRWConc on the work site, the moisture provided during setting and compaction must be determined with the modified proctor test after saturation.

Spanish regulations on roads and structural concrete, such as PG-3 [9] or EHE [10], allow the use of recycled aggregates. Even so, the requirements are the usual ones for natural aggregates, not encouraging their use in the construction site.

Baghini et al. [11] mixed CDW with contents between 0-6\% Portland cement and 0-6\% bitumen emulsion, obtaining exceptional characteristics for use in road bases. Thus, high indices of CBR, UCS and flexural strength were obtained. Specimens were manufactured with 3\% emulsion and $4 \%$ cement, and other samples with a cement content of $4.0 \%$. When subjected to 12 wet-dry cycles, the emulsion test specimens showed a $179.4 \%$ water reduction, a $256.3 \%$ volumetric change and a $211.95 \%$ weight change compared to the other series. According to creep and wheel test results, the deformation resistance is significantly improved with the addition of $4 \%$ cement and 3\% bitumen emulsion. European Regulation (EU) No. 305/2011 [12] requires all RA to carry the CE label. 
For Agrela and others [13], there is little research on AR mixed with cement in road pavements despite the environmental benefits of their use. AR in comparison with natural aggregates show lower density, higher water absorption and lower resistance to fragmentation, although this is not important when mixed with cement.

The content of soluble sulphates expressed as $\mathrm{SO}_{3}$ ion should be less than $0.8 \%$ [9] to be mixed with the cement. The South African Department of Transport and Public Works [14], has used a layer of AR with 3\% cement as a stabilized soil.

\section{Materials and methods}

Research has been focused on artificial aggregate from the crushing of structural concrete waste in selective demolitions processed at the CDW treatment plant in Calvarrasa de Abajo (Salamanca, Spain). The plant performs treatments for the recovery of CDW, such as crushing, classification and separation of fractions by triage. The stone fraction of the structural concrete CDW, CDWRConc, rejects the non-stone fraction, soils, stones and other materials such as insulations. Thus, CDWRConc is obtained from concrete, concrete products, mortar and prefabricated concrete parts.

Structural concretes are mostly derived from buildings, usually designed for stresses of 25 $\mathrm{MPa}$ at 28 days [10]. It has a dosage composed of natural siliceous aggregate, Portland cement and chemical additives as fluidizers. This study analyses the use of CDWRConc in base layers in sustainable road infrastructures, and in others with similar traffic distributions such as urban roads and car parks. Sustainable roads are routes that cross places of great natural value with high environmental limitations on aggregate extraction and that have a low intensity of heavy traffic. The use of CDWRConc as an artificial recycled concrete aggregate (GARConc) in a continuous granular base layer has been investigated. The use of the CDWRConc in the production of recycled cement soil (CSRConc) has also been studied. Thus, granular materials (CDWRConc), cement and water were mixed.

\section{Results and discussion}

The classification of aggregates for granular layers and those treated with hydraulic conglomerates, for use in structural layers of pavements, is done in accordance with standard UNE-EN 132442:2003+A1 [15]. According to the results shown in Table 1, the aggregates are classified as $(\mathrm{Rc}+\mathrm{Ru}) 90, \mathrm{X1-}$, FL1-.

Table 1. Contents in the ZARHorm of the components in the recycled coarse aggregates

\begin{tabular}{ccc}
\hline Components & Contents (\%) & Categories \\
\hline $\mathrm{Rc}$ & 89.7 & Rc80 \\
$\mathrm{Rc}+\mathrm{Ru}$ & 100.0 & Rcu90 \\
$\mathrm{X}$ & $<0.1$ & \\
$\mathrm{FL}$ & $<0.1$ & \\
\hline
\end{tabular}

where:

$\mathrm{Rc}=$ concrete, concrete products, mortar, concrete masonry parts.

$\mathrm{Ru}=$ untreated aggregates, natural stone Aggregates treated with hydraulic binders.

$\mathrm{FL}=$ Floating material in volume.

$X=$ Other: cohesive materials (clay and soil), metals (ferrous and non-ferrous), wood, non-floating plastics and rubber, gypsum. 
The GARConc components can be seen in figure 1.

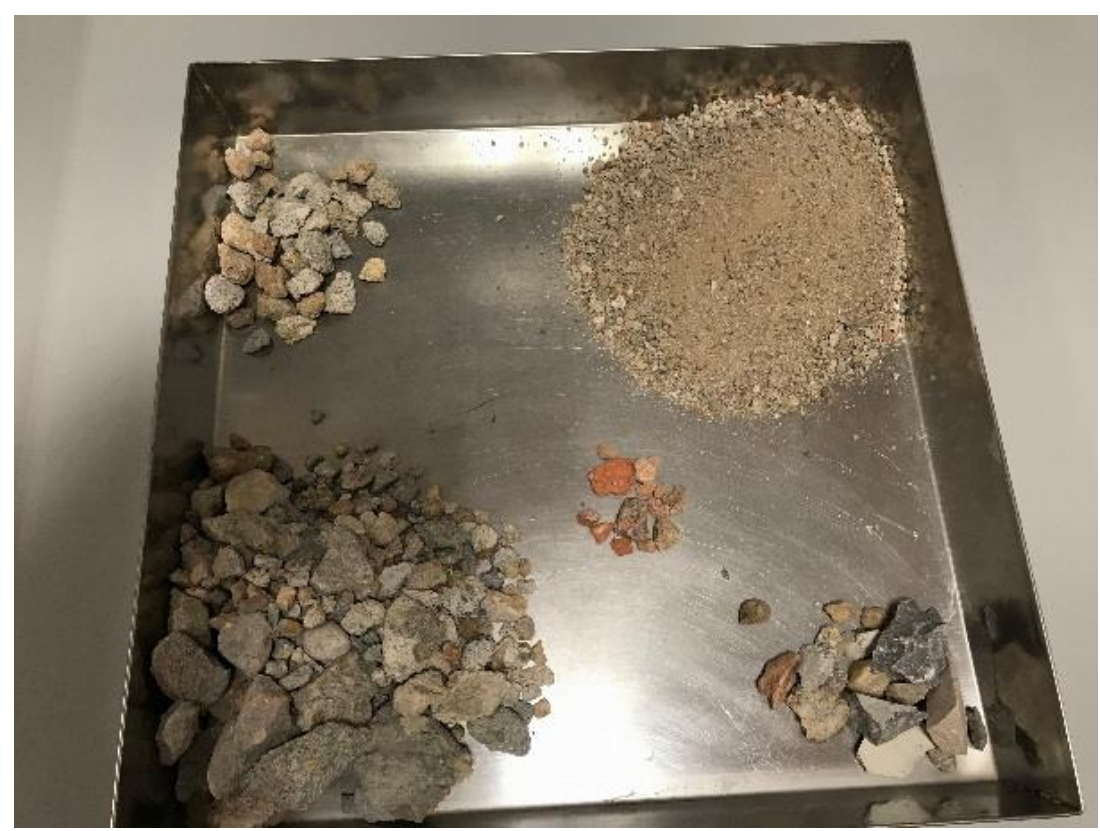

Figure 1. Components of the GARConc Recycled Harvest

Table 2 shows the distribution of particles in the GARConc. Values of $\mathrm{Cu}=75.0$ and $\mathrm{Cc}=3.1$ have been obtained. The high value of the uniformity coefficient shows the high size variation obtained in the unclassified crushing. The curvature coefficient defines the GARConc as well graded and with high compactness.

Table 2. Aggregate type and particle size distribution characteristics of the GARConc

\begin{tabular}{cccccccccc}
\hline $\begin{array}{c}\mathrm{D}_{10} \\
(\mathrm{~mm})\end{array}$ & $\begin{array}{c}\mathrm{D}_{30} \\
(\mathrm{~mm})\end{array}$ & $\begin{array}{c}\mathrm{D}_{50} \\
(\mathrm{~mm})\end{array}$ & $\begin{array}{c}\mathrm{D}_{60} \\
(\mathrm{~mm})\end{array}$ & $\mathrm{C}_{\mathrm{u}}$ & $\mathrm{C}_{\mathrm{c}}$ & $\begin{array}{c}\% \\
\text { Fines }\end{array}$ & $\begin{array}{c}\text { \% Sand } \\
\text { Size }\end{array}$ & $\begin{array}{c}\text { \% (4.75-9.5) } \\
\mathrm{mm}\end{array}$ & $\begin{array}{c}\text { \% (9.5-40) } \\
\mathrm{mm}\end{array}$ \\
\hline 0.08 & 1.0 & 4.0 & 6.0 & 75.0 & 3.1 & 11.1 & 56.1 & 11.9 & 32 \\
\hline
\end{tabular}

The granulometric curve of the GARConc, according to standard UNE EN 933-1 [16], is shown in figure 2. Also included is the tolerance curve for ZA $0 / 20$ [9], which is the artificial grading with a minimum size of $0 \mathrm{~mm}$ and a maximum of $20 \mathrm{~mm}$.

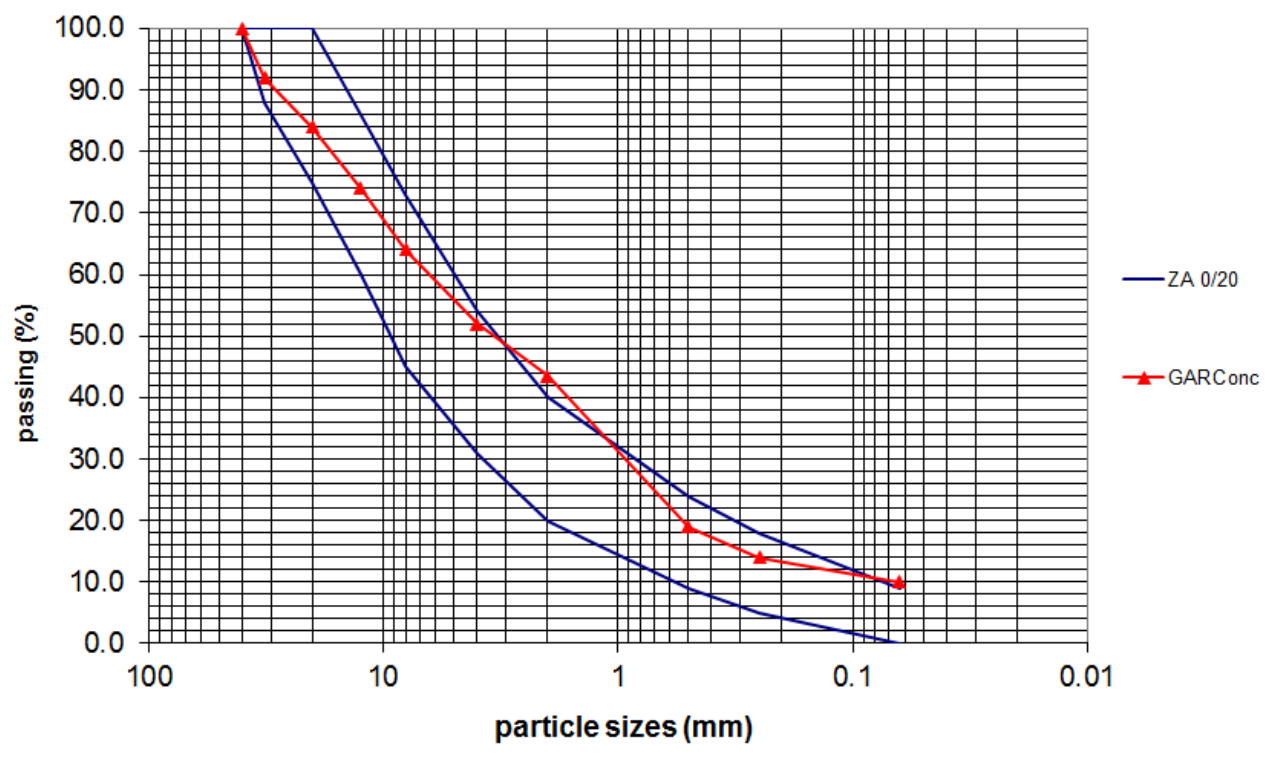

Figure 2. GARConc and ZA 0/20 granulometric curves 
The granulometric curve of the GARConc complies with the specifications of the ZA 0/20 grading. The tolerances [6] are $\pm 2 \%$ for the $0.063 \mathrm{~mm}$ and $\pm 6 \%$ for the rest. In the GARConc the $2 \mathrm{~mm}$ sieve is $3.5 \%$ above the $2 \mathrm{~mm}$ sieve and $1.0 \%$ on the $0.063 \mathrm{~mm}$ sieve, so the tolerances are satisfied. The curve takes the typical shape of the crushing of siliceous aggregates, with a deficit of intermediate sizes in the sand fraction on the $\# 2 \mathrm{~mm}$ sieve. The heterogeneity of the material, coming from the crushing of different types of concrete, makes it difficult to obtain average granulometries. GARConc is classified as GA 75 [15]. It is a crushed gravel with a minimum size of $0 \mathrm{~mm}$ and a pass through the sieve of $6.3 \mathrm{~mm}$ between $75-99 \%$. The physical parameters of the CDWRConc are shown in Table 3.

Table 3. Physical parameters for CDWRConc

\begin{tabular}{cccccccc}
\hline $\mathrm{SE}_{4}$ & $\mathrm{LA}$ & $\mathrm{OM}$ & $\mathrm{SS}$ & $\mathrm{d}\left(\mathrm{g} / \mathrm{cm}^{3}\right)$ & $\mathrm{AC}(\%)$ & LL & PI \\
\hline 51.5 & 43 & 0.14 & 1.1 & 6.0 & 5.1 & -- & $\mathrm{NP}$ \\
\hline
\end{tabular}

where

$\mathrm{SE}_{4}=$ sand equivalent, UNE-EN 033-8 [17].

LL= Liquid limit UNE 103103 [18].

PI = Plastic limit UNE 103104 [19].

LA = Los Angeles coefficient, UNE-EN 1097-2 [20].

$\mathrm{OM}=$ organic matter content, UNE 1032204 [21].

SS = soluble salt content, UNE 103205 [22].

d, AC = particle density and water absorption, UNE-EN 1097-6 [23].

The quality of the fines, expressed as $\mathrm{SE}_{4}$ sand equivalent, gives a value of 51.5 satisfying the required values in granular layers. Atterberg limits classify CDWRConc as not plastic.

Fragmentation resistance offers an LA coefficient of 43.0. This value complies with the maximum recommended threshold [9] for an AADTh of less than $50 \mathrm{vhp} / \mathrm{d}$, as usually found in road systems in sensitive environments. The organic matter test provided a $0.14 \%$ value.

The content of soluble salts dissolved in distilled water was $1.1 \%$. Thus, additional waterproofing or drainage measures should be adopted in the upper layers of the pavement to avoid water infiltration into the layer formed with CDWRConc.

The specific weight of the particles obtained was $2,615 \mathrm{~g} / \mathrm{cm}^{3}$ and the water absorption coefficient was $5.1 \%$. The CDW have a high-water absorption coefficient, higher than that natural aggregates. In the CDWRConc the high absorption is associated with the porosity of the concrete which is the main component.

The curve of the modified Proctor test, UNE 103501 [24], which can be seen in figure 3, offers a maximum density of $1,992 \mathrm{~g} / \mathrm{cm} 3$ and an optimum moisture content of $10.6 \%$. The shape of the curve is practically horizontal, variations in moisture produce small increases in density. This is due to the high absorption and that the test procedure does not consider the previous saturation of the aggregates. 


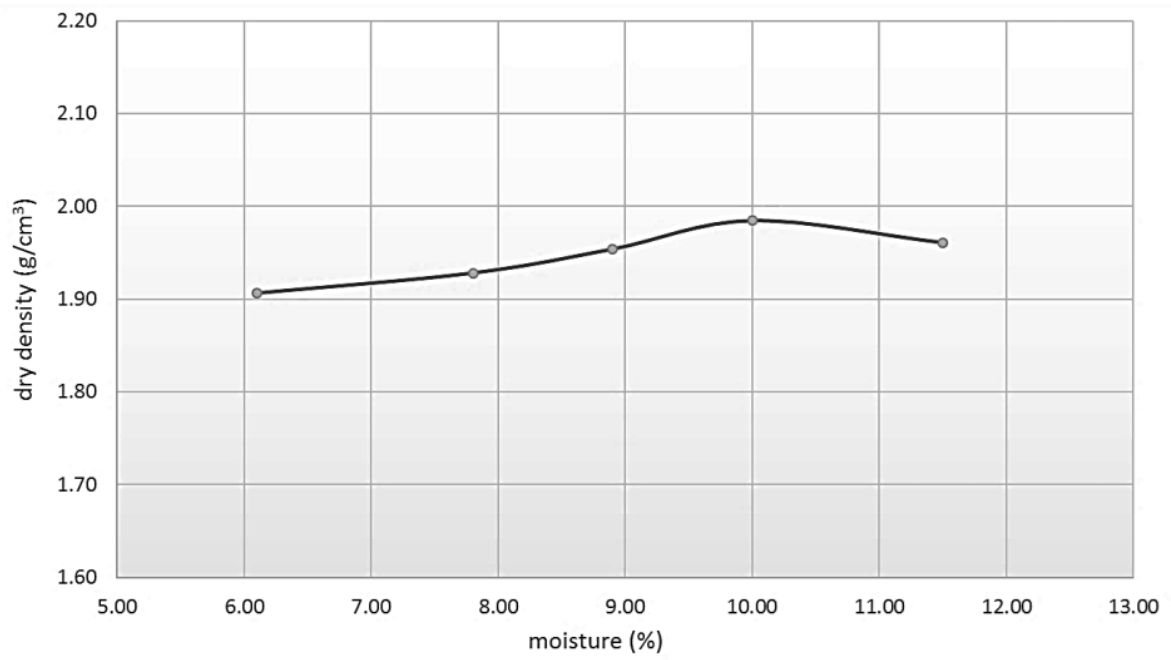

Figure 3. GARConc Modified Proctor

To achieve a $100 \%$ compaction degree of the modified Proctor test on the construction site, the GARConc must be previously watered. A humidity correction must be performed, providing an excess of water above the optimum equal to the absorption coefficient. As can be seen in Figure 4, the CBR index, UNE 103502 [25], for a degree of compaction of 100\% of the modified Proctor density, is 193.0. GARConc has a high bearing capacity, suitable for use as a granular base layer.

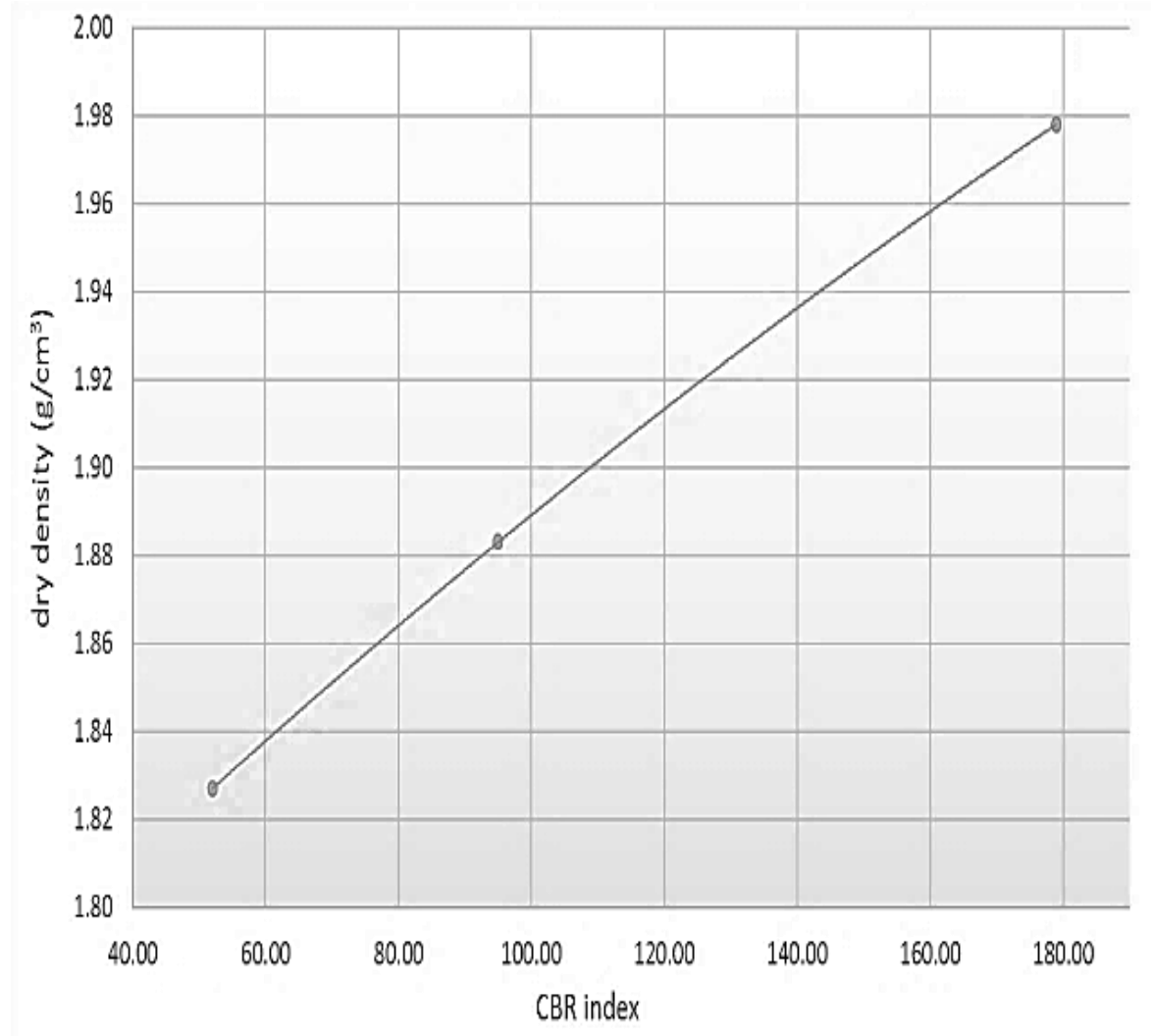

Figure 4. GARConc CBR index

Another use of the CDWRConc is the manufacture of soil-cement, CSRConc, as a structural layer in road pavements. The chemical composition of GARConc and its non-plastic character are suitable for soil-cement. As can be seen in figure 5, the granulometric test classifies [6] the CSRConc as SC40 in accordance with [6]. The existence of a coarse fraction, with 80 to $100 \%$ screening by the $40 \mathrm{~mm}$ sieve, allows for use below the pavement level. 


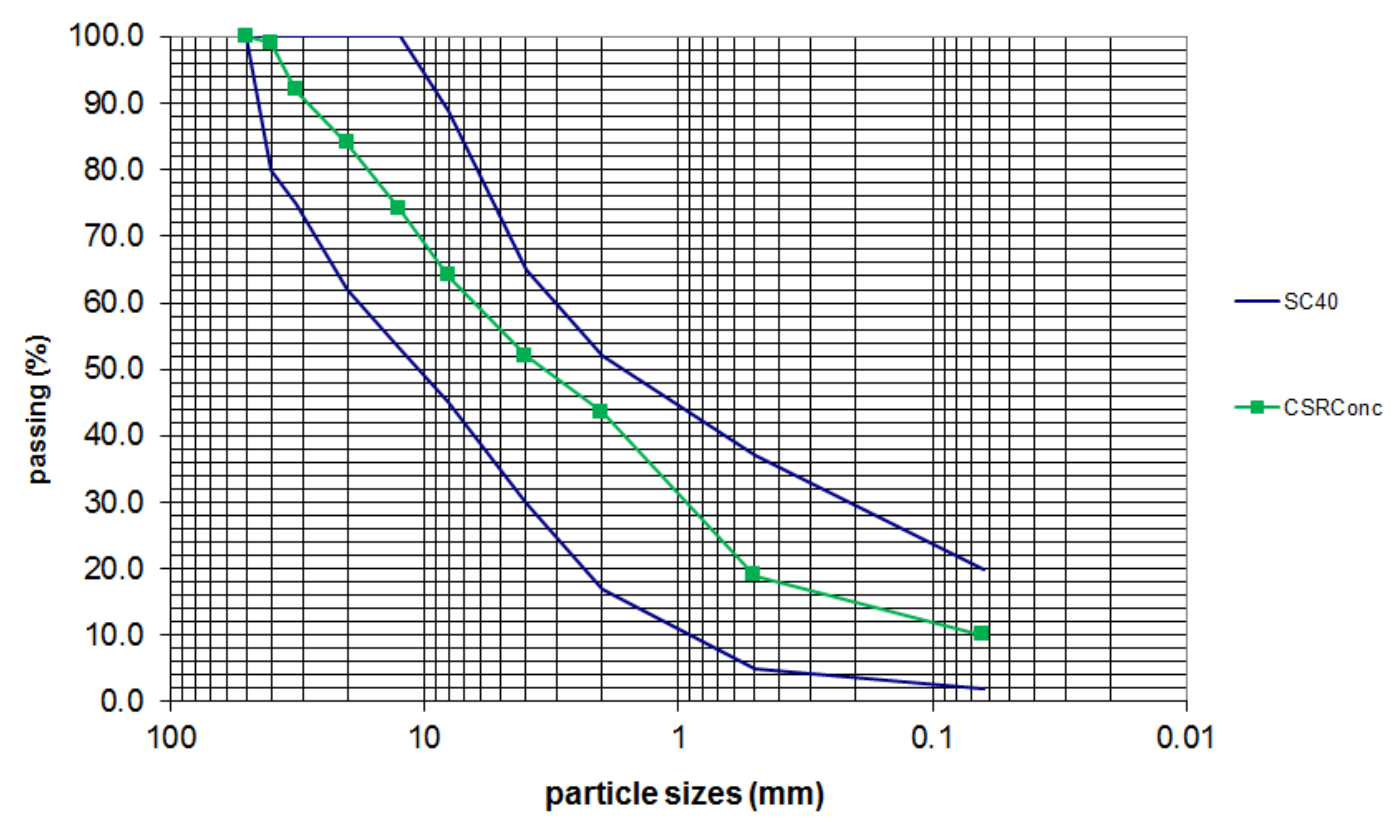

Figure 5. CSRConc and SC40 granulometric curves

The binder used was cement type CEMII/B-M (V-L) 32.5R [26]. It is a composite Portland cement, with a clinker content between $65-79 \%$ and $21-35 \%$ of additions such as siliceous fly ash and limestone. The modified Proctor of the mixture is shown in Figure 6, with values of 2.023 $\mathrm{g} / \mathrm{cm}^{3}$ of maximum density and $8.0 \%$ of optimum moisture.

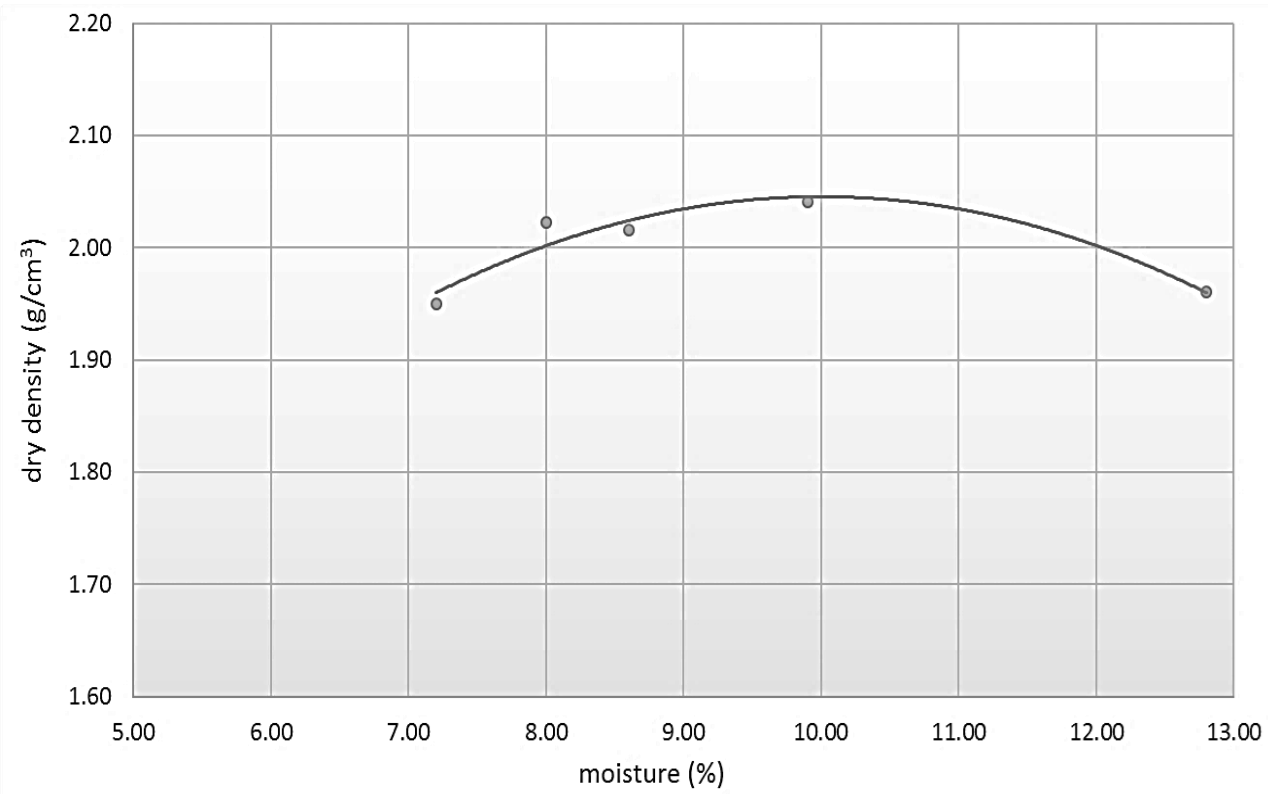

Figure 6. CSRConc Modified Proctor

The curve of the modified Proctor test at CSRConc is also horizontal, behavior associated with the absorption of the aggregates. The manufactured specimens have a cement content of $3.0 \%$ with ruptures at 3,7 and 28 days. The specimens were compacted with an energy corresponding to $98 \%$ of the modified Proctor. Figure 8 shows the UCS values obtained at different ages. The best fit is a logarithmic curve, a model that captures the largest increases in initial resistances. 


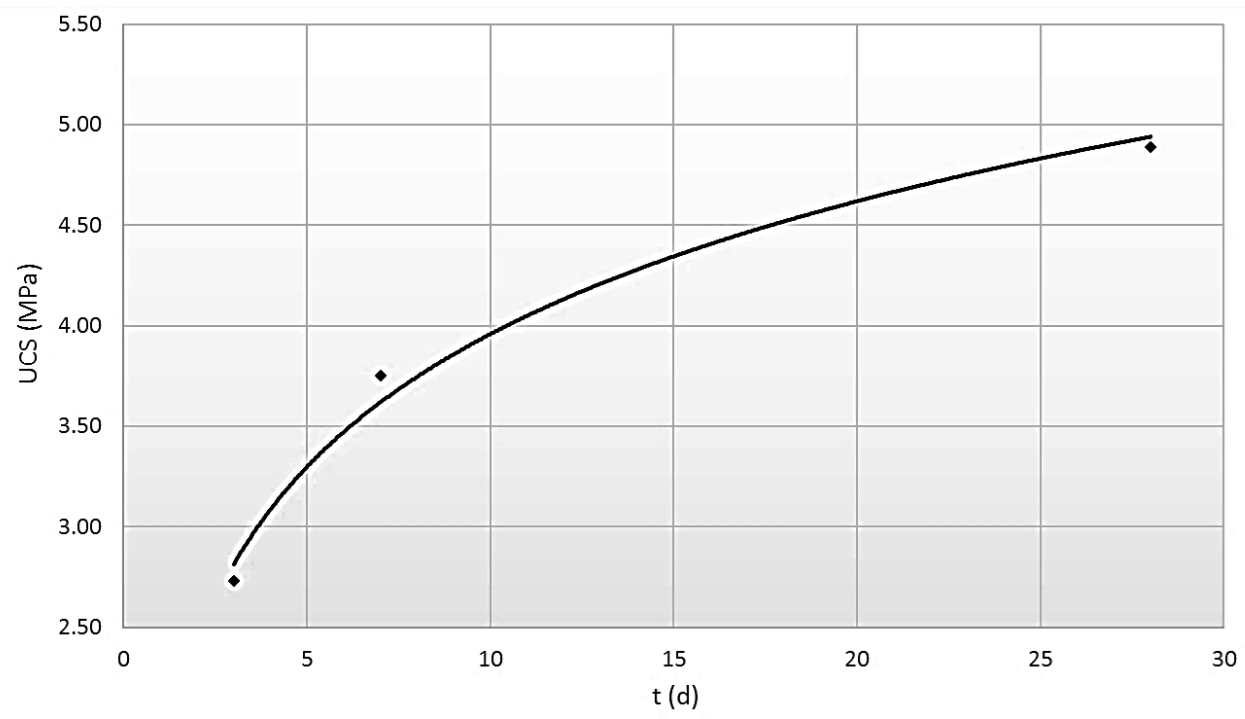

Figure 7. CSRConc UCS curve

The model equation is:

$$
\mathrm{UCS}=0.9529 \ln (\mathrm{t})+1.7646 \quad \mathrm{R}^{2}=0.9887
$$

With the UCS in MPa and the time in days. The function has a domain between $2.7-4.9 \mathrm{MPa}$ and 3 - 28 days. UCS meets the requirements as a base layer for pavements [9] , UCS $\geq 2.5 \mathrm{MPa}$ (7d). Figure 8 shows the ratio $\mathrm{d}$ - UCS. It is directly proportional, with the higher values of $\mathrm{d}$ and UCS corresponding. The high initial values of UCS $>1.5$ (3d), allow the temporary passage of light vehicles through the roadbed made with CSRConc 3 days after paving.

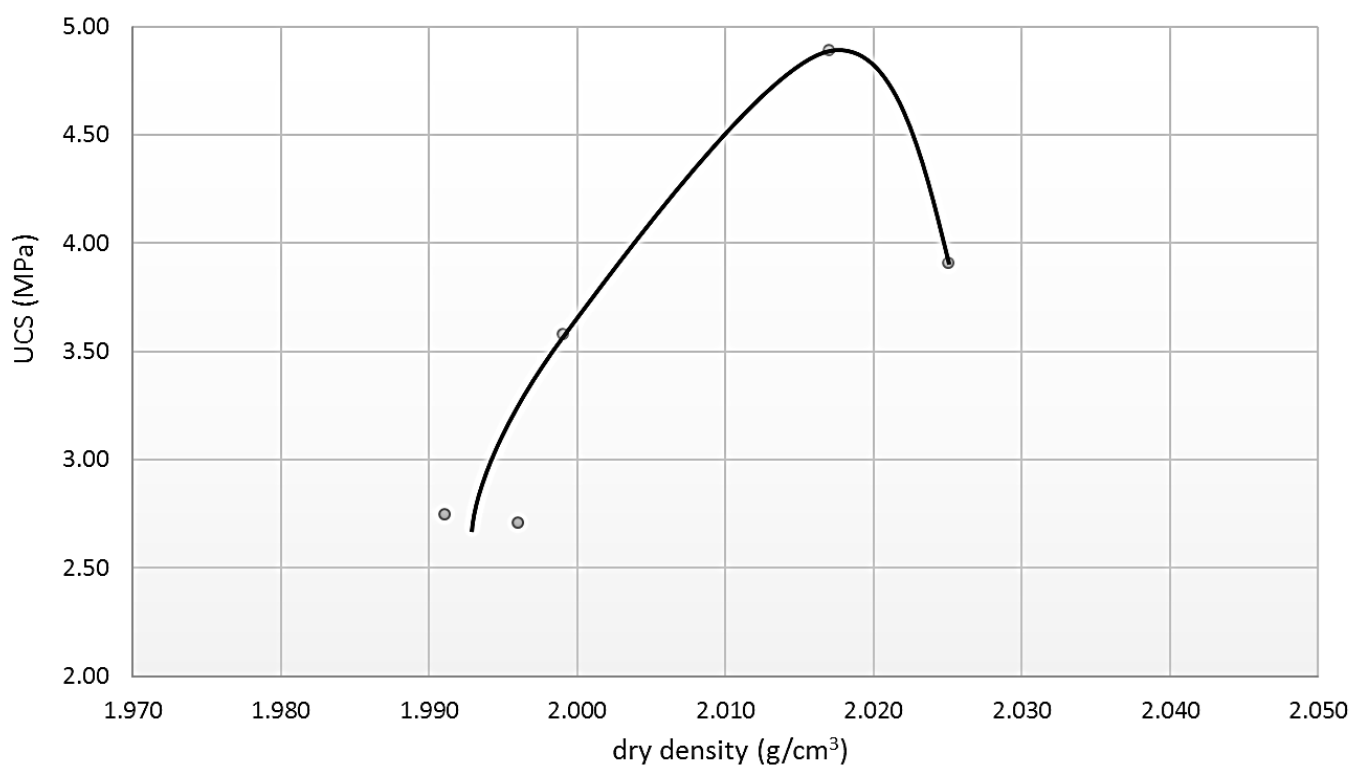

Figure 8. Relationship between dry density - UCS in CSRConc

\section{Conclusion}

This research studies the use of CDWConc. They are the CDW stone fraction corresponding to concrete, which is obtained by crushing structural concrete, concrete products, mortar and prefabricated concrete parts. Among the possible uses, the use in pavement base layers as GARConc artificial grading and CSRConc recycled cement soil has been investigated. 
The results obtained recommend the use of GARConc and CDWConc in sustainable road infrastructures, which are routes that cross places of great natural value with high environmental limitations on aggregate extraction and that have a low intensity of heavy traffic. The following conclusions have been obtained:

- $\quad$ CDWConc can be classified as (Rc+Ru)90, X1-, FL1-, containing concrete, concrete products, mortar, concrete masonry pieces, untreated aggregates, natural stone and aggregates treated with hydraulic conglomerates greater than $90 \%$ and less than $1 \%$ of floating material and other materials.

- The modified Proctor test at CDWRConc lacks sensitivity. There are small variations in density for different moistures, behavior associated with the high absorption coefficient.

- Tests at CDWConcr show the quality of the fines and their non-plastic character, the low organic matter content and a high CBR value.

- This research has detected soluble salt contents in the CDWRConc. Thus, waterproofing or drainage measures should be adopted to prevent water infiltration from the upper layers of the pavement to the layers formed with CDWRHorm.

- The GARConc artificial sieve, made of CDWRConc, is classified as ZA 0/20 and GA 75, with a sieve of $75-100 \%$ by the $20 \mathrm{~mm}$ sieve. Tests prove the adequacy of the material as a granular base layer.

- Additional wetting of the layers with GARConc should be carried out, adding to the optimum of the modified Proctor the corresponding to the absorption coefficient, around $5.0 \%$. The saturation of the material ensures compliance with the degree of compaction compared with the modified Proctor.

- The CSRConc is classified as SC40 cement soil.The granulomeric test shows the existence of a coarse fraction, with a sieve between $80-100 \%$ through the $40 \mathrm{~mm}$ sieve. High values of UCS > 2.5 MPa (7d) have been obtained for a cement content of $3.0 \%$ and a resistance to fragmentation $\mathrm{LA}=43$.

- The CSRConc tests allow for use as a base on the roadbed. The high value of LA limits the use to low traffic, with an AADTh $<50 \mathrm{vhp} / \mathrm{d}$ such as infrastructures in sensitive environments, urban roads and car parks.

- The CSRConc tests allow for use as a base on the roadbed. The high value of LA limits the use to low traffic, with an AADTh $<50 \mathrm{vhp} / \mathrm{d}$ such as infrastructures in sensitive environments, roads in urban roads and parking lots.

- The high initial UCS values at the CSRConc allows light vehicles to transit over the platform after 3 days.

Author Contributions: All authors have read and agree to the published version of the manuscript. Data curation, E.T.-L.-Z. and A.R.-M.; formal analysis, E.T.-L.-Z.; investigation, E.T.-L.-Z. and A.R.-M.; methodology, E.T.-L.-Z.; project administration, E.T.-L.-Z.; resources, A.R-M..; software, E.T.-L.-Z. and A.R.M.; supervision, E.T.-L.-Z., Á.V.-Z. and M.Á.C.-P.; validation, E.T.-L.-Z., Á.V.-Z. and M.Á.C.-P.; writingoriginal draft, E.T.-L.-Z.; writing-review and editing, E.T.-L.-Z., Á.V.-Z. and M.Á.C.-P.

Funding: This research received no external funding.

Conflicts of Interest: The authors declare no conflict of interest. 


\section{Abbreviations}

The following abbreviations are used in this manuscript:

RA

Recycled Aggregate.

$\mathrm{CDW}$

Construction and Demolition Waste.

CDWRConc Construction and Demolition Waste from Recycled Concrete.

GA Graded aggregate.

GARConc Graded aggregate Recycled Concrete.

E Compressive modulus (MPa).

$v \quad$ Poisson coefficient.

$\mathrm{Cu} \quad$ Uniformity coefficient.

Cc Curvature coefficient.

ZA 0/20 Artificial turf with minimum and maximum sizes of 0 and $20 \mathrm{~mm}$ respectively.

GA $75 \quad$ Aggregate combined with a passage through the largest sieve of $75-99 \%$.

CBR California Bearing Ratio.

CSRConc Cement Soil Recycled Concrete.

SC40 Cement Soil with a maximum size of $40 \mathrm{~mm}$.

UCS Unconfined Compressive Strength (MPa).

$\mathrm{SE}_{4} \quad$ Sand equivalent.

LL $\quad$ Liquid Limit.

PI Plastic Limit.

LA Los Angeles Wear Coefficient.

OM Organic matter content (\%).

SS Soluble salt content (\%).

d Particle density $\left(\mathrm{g} / \mathrm{cm}^{3}\right)$.

AC Water absorption (\%).

AADTh Annual Average Daily Traffic of heavy vehicles $\left(\mathrm{vh}_{\mathrm{p}} / \mathrm{d}\right)$

$v_{\mathrm{p}} \quad$ Heavy vehicles.

\section{References}

1. Directive 2008/98/EC of the European Parliament and of the Council of 19 November 2008 on waste and repealing certain Directives. Official Journal of the European Union 22.11.2208, L $312 / 3$.

2. Arshad, M.; Ahmed, M. F. Potential use of reclaimed asphalt pavement and recycled concrete aggregate in base/subbase layers of flexible pavements. Construction and Building Materials. 2017, 151, 83-97. DOI: 10.1016/j.conbuildmat.2017.06.028

3. Spanish Waste Management Framework Plan 2016-2022 PEMAR [2].

4. Amending Decision 2000/532/EC on the list of waste pursuant to Directive 2008/98/EC of the European Parliament and of the Council, 18 December 2014. Official Journal of the European Union 30.12.2014, L 370/44. 
5. Ebrahim Abu El-Maaty Behiry, A. Utilization of cement treated recycled concrete aggregates as base or subbase layer in Egypt. Ain Shams Engineering Journal. 2013, 4, 661-673. DOI: 10.1016/j.asej.2013.02.005

6. Catalogue of pavements and work units with recycled aggregates from Construction and Demolition Waste, UCOPress Editorial Universidad de Córdoba, 2017.

7. Cartuxo, F.; De Brito, J.; Evangelista, L.; Jiménez, J. R.; Ledesma, E. F. Increased Durability of Concrete Made with Fine Recycled Concrete Aggregates Using Superplasticizers. Materials. 2016, 9[2], 98. DOI: 10.3390/ma9020098

8. Guide to the use of recycled aggregate and recommendations for its purchase, Innovative Business Grouping for Efficient Construction (AEICE), 2018.

9. Ministry of Public Works. General Specifications for Roads and Bridges Works PG-3; 3th Part Explanations; Ministry of Public Works: Madrid, Spain, 2014; pp. 50-312.

10. Code on Structural Concrete (EHE-08), Ministerio de Fomento, Gobierno de España, 2010.

11. Baghini, M. S.; Ismail, A.; Bin K.; Mohamed R. Evaluation of cement-treated mixtures with slow setting bitumen emulsion as base course material for road pavements. Construction and Building Materials. 2015, 94, 323-336. DOI: 10.1016/j.conbuildmat.2015.07.057

12. Regulation (EU) no 305/2011 of the European Parliament and of the Council of 9 March 2011 laying down harmonised conditions for the marketing of construction products and repealing Council Directive 89/106/EEC, Official Journal of the European Union 4.4.2011, L 88/5.

13. Agrela, F.; Barbudo, A.; Ramírez, A.; Ayuso, J.; Carvajal, M.D.; Jiménez, J.R. Construction of road sections using mixed recycled aggregates treated with cement in Malaga, Spain. Resources, Conservation and Recycling, 2012, 58, 98-106. DOI: 10.1016/j.resconrec.2011.11.003.

14. Solutions for ecological paving and sustainable materials. State of the art best practices, challenges and new and emerging technologies Technical Committee D.2 Road pavements. World Road Association (PIARC). La Defense Cedex, France, 2019.

15. UNE-EN 13242:2003+A1. Aggregates for unbound and hydraulically bound materials for use in civil engineering work and road construction; AENOR: Madrid, Spain, 2008.

16. UNE-EN 933-1. Test for geometrical properties of aggregates. Part 1: Determination of particle size distribution. Sieving method; AENOR: Madrid, Spain, 2012.

17. UNE-EN 933-8:2012+A1:2015. Tests for geometrical properties of aggregates. Part 8: Assessment of fines. Sand equivalent test. Madrid, Spain, 2016.

18. UNE 103103. Determination of the Liquid Limit of a Soil; AENOR: Madrid, Spain, 2019.

19. UNE 103104. Determination of the Plastic Limit of a Soil; AENOR: Madrid, Spain, 2019.

20. UNE-EN 1097-2. Tests for mechanical and physical properties of aggregates. Part 2: Methods for the determination of resistance to fragmentation, AENOR: Madrid, Spain, 2010.

21. UNE 103 204. Organic matter content of a soil by the potassium permanganate method, AENOR: Madrid, Spain, 2019.

22. UNE 103205. Determination of soluble salts content in soils, AENOR: Madrid, Spain, 2019.

23. UNE-EN 1097-6. Tests for mechanical and physical properties of aggregates. Part 6: Determination of particle density and water absorption, AENOR: Madrid, Spain, 2014.

24. UNE 103501. Geotechnics. Compaction Test. Modified Proctor; AENOR: Madrid, Spain, 1994.

25. UNE 103502. Test Method for Determining in a Soil the California Bearing Ratio (CBR) Index; AENOR: Madrid, Spain, 1995.

26. Ministry of Public Works. Instruction for the reception of cements RC-16. (2016). 